\title{
Characterization of Sintered Aluminium Reinforced with Ultrafine Tungsten Carbide Particles
}

\author{
Omid Emadinia ${ }^{1,2, *(\mathbb{D}}$, Maria Teresa Vieira ${ }^{3}(\mathbb{C})$ and Manuel Fernando Vieira ${ }^{1,2}$ (D) \\ 1 Department of Metallurgical and Materials Engineering, Faculty of Engineering, University of Porto, \\ Rua Dr. Roberto Frias, 4200-465 Porto, Portugal; mvieira@fe.up.pt \\ 2 LAETA/INEGI, Institute of Science and Innovation in Mechanical and Industrial Engineering, \\ Rua Dr. Roberto Frias, 4200-465 Porto, Portugal \\ 3 Centre for Mechanical Engineering, Materials and Processes, Department of Mechanical Engineering, \\ University of Coimbra, Pinhal de Marrocos, 3030-788 Coimbra, Portugal; teresa.vieira@dem.uc.pt \\ * Correspondence: omid.emadinia@fe.up.pt; Tel.: +351-220-413-111
}

Received: 7 October 2020; Accepted: 21 October 2020; Published: 25 October 2020

check for updates

\begin{abstract}
The strengthening effect on aluminium (Al) by ultrafine particles of tungsten carbide (WC) after compacting and sintering was evaluated. The Al- 1 vol.\% WC mixture was prepared through a high-speed stirring technique, called assisted sonication. In this study, the effects of compacting, sintering temperature and holding time were evaluated by composite microstructural characterization and by mechanical tests. The characterizations involved electron dispersive spectroscopy and X-ray diffraction techniques for phase identification; electron backscattered diffraction for crystallographic analysis; backscattered electrons and secondary electrons imaging for failure and wear studies. In all composites, hardness was determined; for the hardest composite, the tensile strength, flexural strength and ball scattering wear resistance were also evaluated. The Al-1 vol.\% WC composite produced by assisted sonication, densified by cold compacting at $152 \mathrm{MPa}$ and sintered at $640{ }^{\circ} \mathrm{C}$ for $2 \mathrm{~h}$ at $5 \times 10^{-4} \mathrm{~Pa}$ (high vacuum) exhibited the highest hardness, associated with an acceptable ductile behavior. This strengthening was associated with the formation of $\mathrm{Al}_{12} \mathrm{~W}$ and grain refinement.
\end{abstract}

Keywords: aluminium; ultrafine tungsten carbide; sintering; strengthening; mechanical properties; microstructure

\section{Introduction}

Aluminium alloy matrix composites are very appealing for human mobility industries due to their high specific properties, allowing the development of faster, more efficient and inexpensive means of transport. Al alloys and particularly their composites are widely used in automotive and aeronautic structural applications $[1,2]$. These metallic matrix composites are usually reinforced with ceramics such as oxides, borides, nitrides and carbides [3]. The tungsten carbide (WC), which has high hardness and rigidity and Young's modulus of 670-700 GPa [4], has attracted some researchers to use this material as a reinforcement of the Al matrix, applying powder metallurgy (PM) [5], accumulative roll bonding [6], stir casting [7] and friction stir processing [8].

Liu et al. [6] commented on the increase in hardness, tensile and wear properties of an AA1060-3 vol.\% WC composite (particles with an average size of almost $3 \mu \mathrm{m}$ ), produced by 13 accumulative roll bonding cycles. This mechanical response was associated with an increase in the number of dislocations, without the formation of new phases. Ravikumar et al. [7] highlighted the efficacy of adding $8 \mathrm{wt} . \%$ of WC $\left(D_{50}=53-75 \mu \mathrm{m}\right.$, mixed by stir casting technique) in the yield and tensile strength of the AA6082-WC composite; however, they mentioned a progressive decrease in density, impact strength and ductility of the composite with increasing reinforcement concentration. These authors did not mention the 
formation of any transformed phase, though they performed X-ray analysis. Huang et al. [8] produced AA5083 composite through friction stir processing to distribute WC particles (with $4 \mu \mathrm{m}$ average size) in the $\mathrm{Al}$ matrix. These authors highlighted the positive effect of increasing WC concentration on hardness, yield and tensile strengths but deteriorating the plastic deformation capacity of the Al matrix. The excellent interfacial bonding between WC reinforcements and the Al matrix, without the formation of reaction products, promotes load transferring as the primary strengthening mechanism; besides, these authors mentioned the formation of nanoparticles that can trigger the pinning effect on dislocation movements (Orowan mechanism) during plastic deformation. Borodianskiy and Zinigrad [9] remarked the influence of WC nanoparticles on grain refinement in pure Al and A356 alloy and the modification effect in the alloy produced by PM and stir casting. These works showed that, as in other metal matrix composites [10], several strengthening mechanisms can be activated in Al-WC composites depending on the characteristics of the reinforcements and processing history, namely, grain refinement, load transferring, dispersion hardening and thermal/modulus mismatch effects.

Powder metallurgy (PM) processes involve a mixing step. Ball milling is the most promising mixing process in order to obtain homogeneous composites [5]. However, the production of Al composites through ball milling, as mixing procedure, should be carried out in an inert or reducing atmosphere to prevent $\mathrm{Al}$ oxidation. The milling process is long; its duration strongly influences densification and strengthening and, generally, the more hours of milling, the better the improvement [11].

Razavi and Mobasherpour [12] produced AA7075-WC composites with different WC contents by ball milling for $20 \mathrm{~h}$ and hot pressing at $300 \mathrm{MPa}$ and $430^{\circ} \mathrm{C}$ for $15 \mathrm{~min}$. Increasing WC amount reduces the relative density and ductility and increases the hardness; the tensile strength reaches the maximum value for a $20 \mathrm{wt}$.\% of WC. Simon et al. [13] mixed Al powders with WC powder particles $\left(D_{50}=1 \mu \mathrm{m}\right)$ by ball milling and found that the prolongation of the milling time increases the density obtained but decreases the wear resistance and hardness for most composites produced. These authors confirmed the formation of $\mathrm{Al}_{12} \mathrm{~W}$ during sintering at $580{ }^{\circ} \mathrm{C}$ in nitrogen for $20 \mathrm{~min}$. Evirgen and Öveçoglu [5] remarked the effectiveness of high-energy ball milling in the hardening and densification of an $\mathrm{Al}-2 \mathrm{Cu}-7 \mathrm{WC}$ (wt.\%) composite produced using elemental powders of $\mathrm{Al}, \mathrm{Cu}$ and WC, with 10, 30 and $3 \mu \mathrm{m}$ average particle sizes, respectively. The mixed powders were cold pressed at $220 \mathrm{MPa}$ and sintered at $650{ }^{\circ} \mathrm{C}$ for $4 \mathrm{~h}$ in an Argon atmosphere. These authors attributed the hardening effect to the formation of the $\mathrm{Al}_{12} \mathrm{~W}$ phase.

This study assesses the effect of processing conditions on the microstructure and mechanical properties of an Al-WC composite produced by powder metallurgy (which involves mixing, compacting and sintering). An innovative aspect of this work is the use of assisted sonification as the mixing method, which allows a significant reduction in time when compared to ball-milling. The use of pure $\mathrm{Al}$ allows more precise identification of the hardening mechanisms involved as it avoids possible hardening by solid solution and second phase. The matrix of Al was reinforced with 1 vol.\% of ultrafine WC powder particles. This small concentration was used to prevent a considerable increase in density and to benefit the effect of WC particles; the cited works have shown that there is a decrease in the mechanical properties of the composites at high WC concentrations. The optimization of the processing conditions is essential to maximize the properties of the composite and enhance its future application.

\section{Materials and Preparation}

Alfa Aesar supplied a $99.8 \mathrm{wt}$.\% pure Al powder. This powder consisted of particles with $\mathrm{D}_{50}$ of $10 \mu \mathrm{m}$ and very irregular morphology, as shown in Figure 1a, due to the gas atomization production process. The Al powder particles were composed of fine polycrystalline grains; Figure $1 \mathrm{~b}$ shows one of these particles with an average grain size of $0.8 \mu \mathrm{m}$. The WC powder, from H.C. Starck Tungsten $\mathrm{GmbH}$, had a purity of $99.8 \%$, a $\mathrm{D}_{50}$ of $0.33 \mu \mathrm{m}$ and an angular shape (Figure 1c). The mixture of $\mathrm{Al}$ powders with $1 \mathrm{vol} . \% \mathrm{WC}$ (5.5 wt.\%) was made using the assisted sonication method. Figure $2 \mathrm{a}$ illustrates the three stages of the dispersion procedure, de-agglomerating WC particles in isopropanol using Ultrasonic bath (BANDELIN electronic, Berlin, Germany) for 15 min (Figure 2(a1)), dispersing Al 
powder particles also in isopropanol (SIGMA-ALDRICH, St. Louis, MO, USA) at $3000 \mathrm{rpm}$ for 5 min (Figure 2(a2)) and then mixing these two dispersions and applying simultaneous dispersing by Ultrasonic bath and 11,000 rpm for $5 \mathrm{~min}$ (Figure 2(a3)), after which the mixture was drained and dried in an oven (EHRET, Emmendingen, Germany) at $80^{\circ} \mathrm{C}$ for $1 \mathrm{~h}$. Figure $2 \mathrm{~b}$ shows that the WC particles were dispersed among the Al powder particles.

The Al-1 vol.\% WC powders mixture was cold compacted by uniaxial compression, with 76 or $152 \mathrm{MPa}$, into discs with diameters of $10 \mathrm{~mm}$ and $30 \mathrm{~mm}$ and height of $3 \mathrm{~mm}$. These discs were sintered under the conditions indicated in Table 1 in a horizontal electric furnace (Termolab, Águeda, Portugal) with an alumina ceramic tube. Similar samples of Al powder were prepared with identical conditions and sintered simultaneously with the composite samples for comparison purposes. From sintered samples, specimens for mechanical tests were prepared by electro-discharge machining.

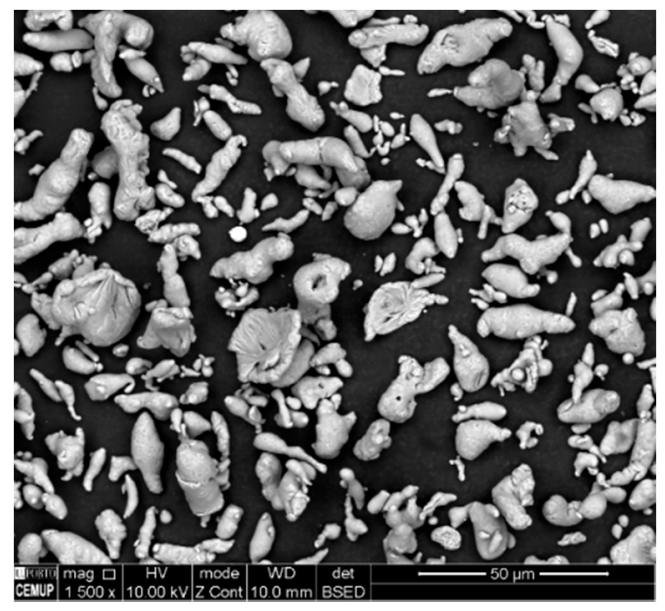

(a)

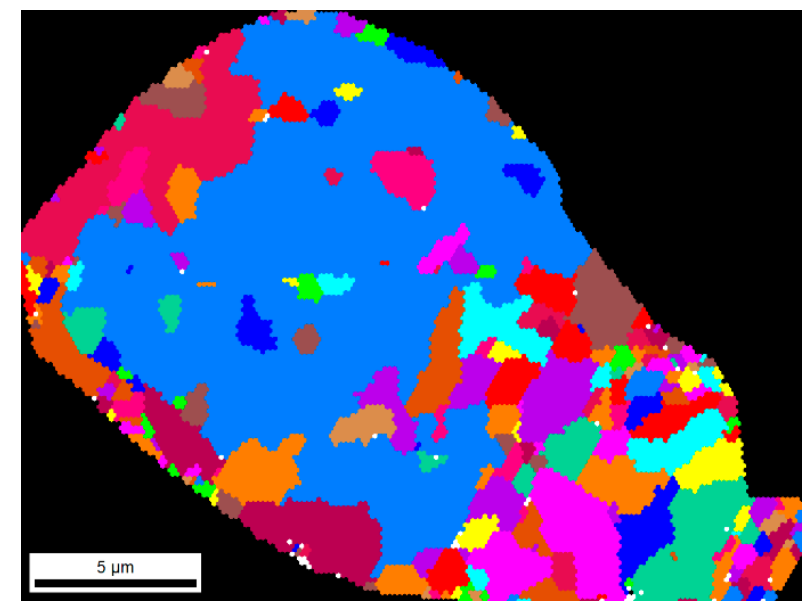

(b)

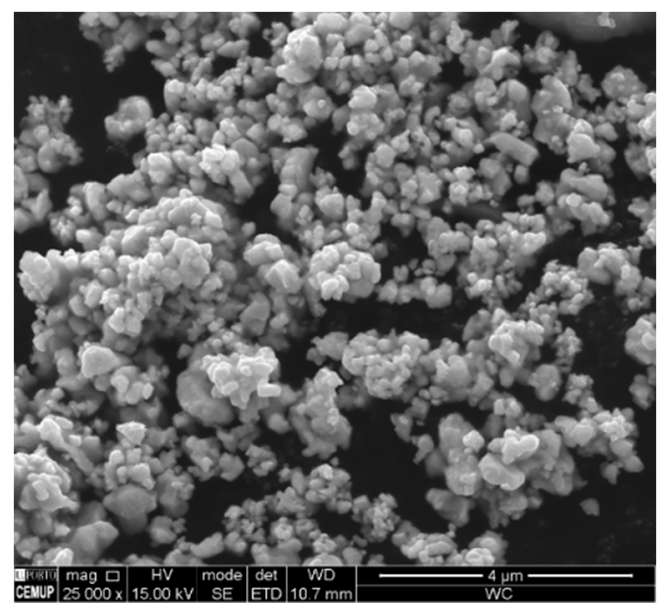

(c)

Figure 1. Microscopic characterization of input materials used in this study: (a) The morphology of $\mathrm{Al}$ powder (SEM/SE image), (b) EBSD grain colour map from an individual Al particle and (c) the tungsten carbide (WC) particles (SEM/SE image).

Microstructural characterization involved optical microscopy (OM), using the Leica DM $4000 \mathrm{M}$ equipment (Leica Microsystems, Wetzlar, Germany) and scanning electron microscopy (SEM), with the FEI-Quanta 400 FEG equipment (FEI Company, Hillsboro, OR, USA), through secondary electrons (SEM/SE) and backscattered electron (SEM/BSE) imaging modes. Electron dispersive spectroscopy (SEM/EDS) (Oxford Instrument, Oxfordshire, UK), as a semi-quantitative analysis, was applied to 
determine the chemical composition of phases. Crystallographic information was obtained by electron backscatter diffraction technique (SEM/EBSD), using TSL-EDAX EBSD Unit and TSL OIM Analysis 5.2 software (EDAX Inc., Mahwah, NJ, USA). Phase identification was performed by X-ray analysis using PANalytical diffractometer (Malvern Panalytical, Malvern, UK) equipped with a CuK $\alpha$ radiation source $(1.540598 \AA)$, carried out with a scanning rate of one second per step, using the X'Pert HighScore Plus software (version 2.2b (2.2.2), Malvern Panalytical, Malvern, UK).
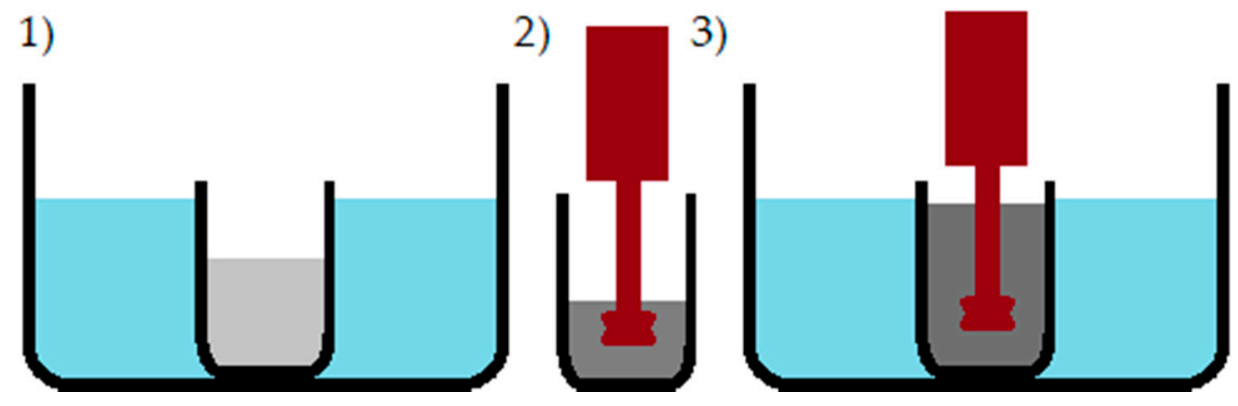

(a)

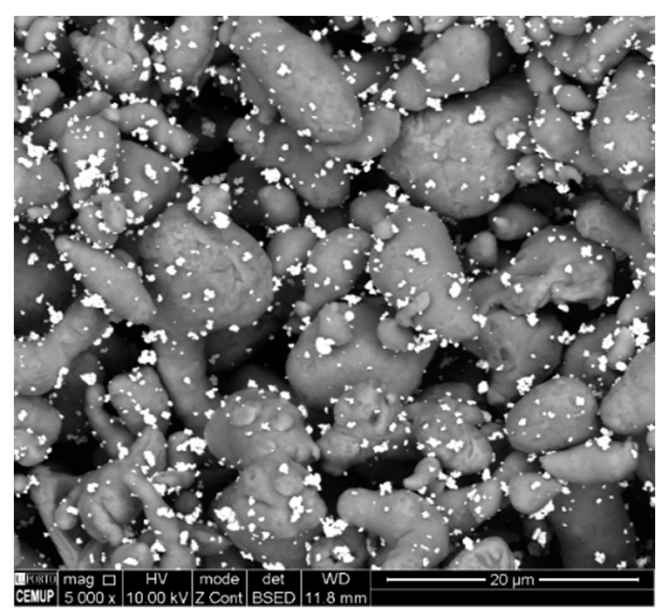

(b)

Figure 2. (a) Mixing procedure: Step 1-dispersion of pristine WC in isopropanol for $15 \mathrm{~min}$ in an ultrasonication bath; step 2-dispersion of Al powder in isopropanol at $5000 \mathrm{rpm}$ for $5 \mathrm{~min}$; and step 3 -mixing of the two dispersions with simultaneous sonication at 11,000 rpm with the mixing vessel is in the ultrasonication bath; (b) SEM/BSE image of the dry Al-1 vol.\% WC mixture.

Table 1. Sintering conditions of non-reinforced $\mathrm{Al}$ and of $\mathrm{Al}-1 \mathrm{WC}$ vol.\% composite.

\begin{tabular}{ccc}
\hline Temperature $\left({ }^{\circ} \mathrm{C}\right)$ & Holding Time (h) & Pressure (Pa) \\
\hline $630{ }^{\circ} \mathrm{C}$ & 2 & $\sim 5 \times 10^{-4}$ \\
$640{ }^{\circ} \mathrm{C}$ & $0.5,1$ and 2 & \\
\hline
\end{tabular}

The mechanical characterization involved microhardness measurements to determine the strengthening effect of WC in Al matrix, carried out using Struers Duramin equipment (Struers, Ballerup, Denmark), at a $0.490 \mathrm{~N}$ load (HV 0.05). Subsequently, the reinforcement effect analysis was complemented by tensile and flexural strength measurements, failure analysis and wear abrasive resistance evaluation of the hardest composite obtained in this study. The tensile and flexural properties were measured by a Shimadzu Table-Top universal tester equipment (SHIMADZU EUROPA GmbH, Duisburg, Germany); the flexural characteristics measured by a three-point bending test. The wear resistance test was performed using a micro ball cratering method (PLINT TE 66 Micro-Scale Abrasion 
tester equipment) (Phoenix Tribology Ltd, Berkshire, England), with a mixture of ionized water and 2 vol. \% of black silicon carbide (with particles of $99.9 \%$ purity and average particle size less than $3 \mu \mathrm{m}$ ).

\section{Results and Discussion}

\subsection{Microstructural Characterization of the Al-1 vol.\% WC Composite}

Figure 3 shows the effect of the holding time on the porosity of the composite. For a holding time of $1 \mathrm{~h}$, the sintered specimen has much larger and more frequent porosities (black regions in the figure) than the one sintered for $2 \mathrm{~h}$. This difference is explained by the positive effect of time on mass transport mechanisms, such as volume diffusion [14], responsible for eliminating porosity. This figure also shows that $2 \mathrm{~h}$ of holding time, even using the lowest compacting pressure, is sufficient to eliminate a significant part of the porosity during sintering. Density analysis, performed by dimensional and weight measurements, revealed a relative density of $65 \%$ and $80 \%$ for the composite specimens produced with $76 \mathrm{MPa} / 630^{\circ} \mathrm{C} / 2 \mathrm{~h}$ and $76 \mathrm{MPa} / 640^{\circ} \mathrm{C} / 1 \mathrm{~h}$, confirming the effectiveness of an increase in sintering temperature in composite densification. The compound produced under the most demanding processing conditions, $152 \mathrm{MPa} / 640^{\circ} \mathrm{C} / 2 \mathrm{~h}$, is the densest, with a relative density of $95 \%$.

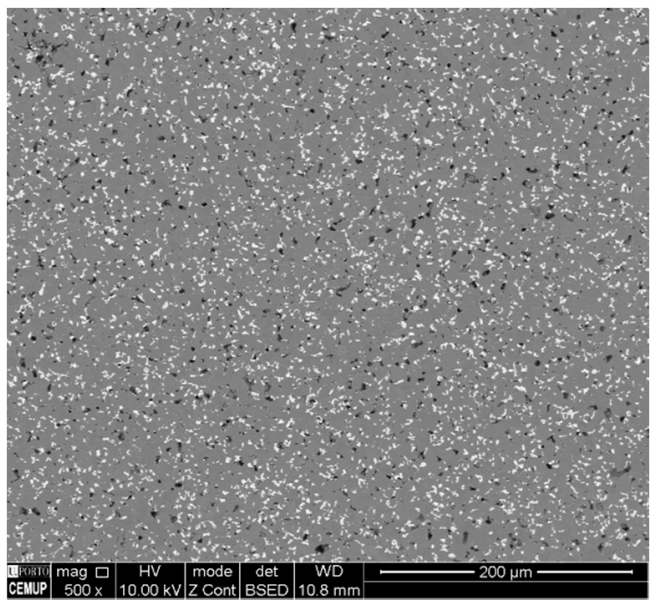

(a)

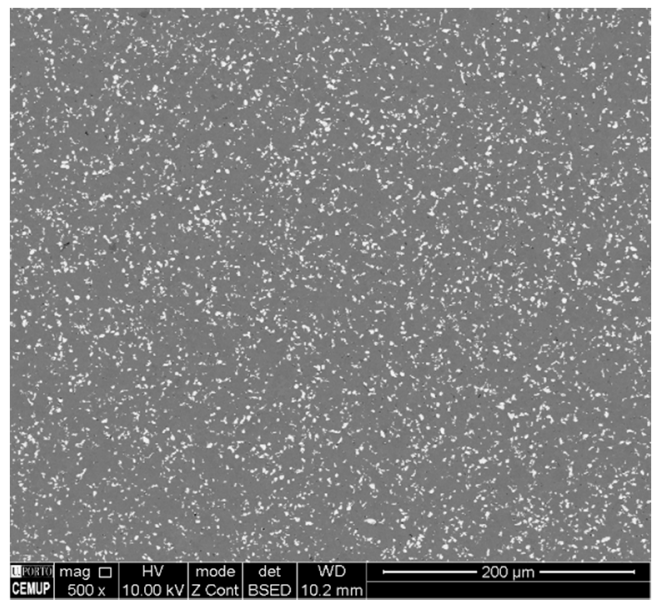

(b)

Figure 3. SEM/BSE images of Al-1 WC vol.\% composites cold compacted at $76 \mathrm{MPa}$ and sintered at $640{ }^{\circ} \mathrm{C}$ in high vacuum $\left(\sim 5 \times 10^{-4} \mathrm{~Pa}\right)$ : (a) Pores (black spots) dispersed in the microstructure of the specimen sintered for $1 \mathrm{~h}$, (b) pore-free microstructure of the specimen sintered for $2 \mathrm{~h}$.

Figure 3 also shows the presence of a new phase (light gray particles). EDS maps were made to characterize this new phase, which is more evident in Figure 4. The EDS maps show that the white areas are composed of $W$ and $C$ and represent the initial WC; the gray areas, which in Figure 4 are larger than the WC particles, are rich in $\mathrm{Al}$ and $\mathrm{W}$. The presence of $\mathrm{C}$ in this phase is practically not detected. These maps confirm the formation of a new phase, consisting of $\mathrm{Al}$ and $\mathrm{W}$, formed during sintering and dispersed in the matrix of $\mathrm{Al}$. This phase is probably $\mathrm{Al}_{12} \mathrm{~W}$, according to the stoichiometry obtained by EDS analysis, which is consistent with other studies $[5,13]$. The $C$ resulting from this reaction appears to be in the crystal lattice of this new phase or formed as $\mathrm{Al}_{4} \mathrm{C}_{3}$ at the interface which has not been detected by SEM techniques, thus further evaluations will be required by high resolution transmission electron microscopy analysis, as future works. The identification of the strengthening mechanisms must consider the formation of $\mathrm{Al}_{12} \mathrm{~W}$.

Moreover, in Figure 3a no cracks or discontinuities were observed at the interface between the second phase and matrix. This good interface bonding is important in improving the mechanical properties of the Al-W composites by the load transfer mechanism. 


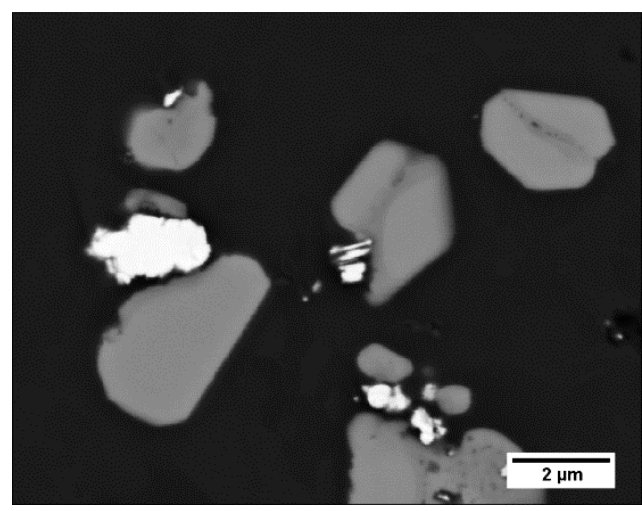

(a)

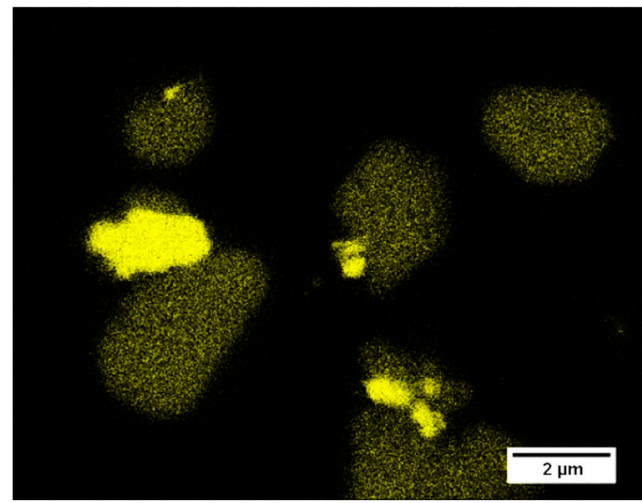

(c)

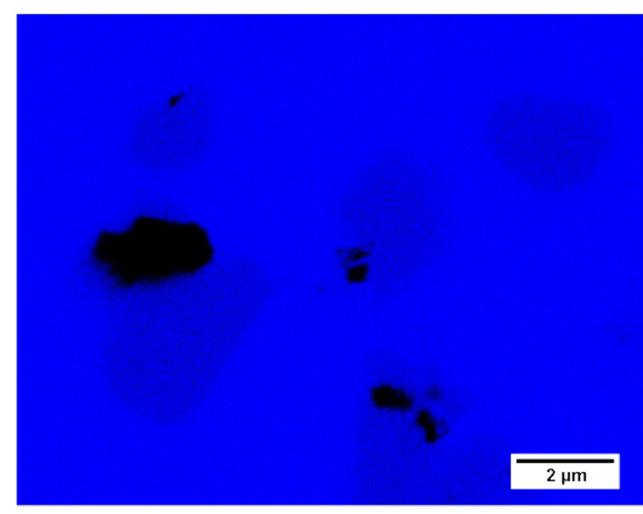

(b)

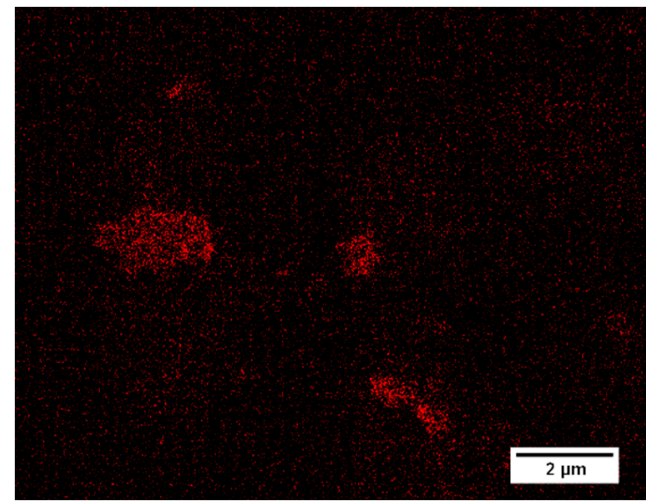

(d)

Figure 4. (a) One area of the composite in which the two types of particles are observed (white and light gray particles). EDS map analysis illustrating the distribution in that selected zone of (b) Al, (c) W and (d) C.

An XRD analysis was performed to verify the phases formed during the sintering step. Figure 5 confirms the presence of the phase $\mathrm{Al}_{12} \mathrm{~W}$ in the composite (indexed by reference pattern number 00-008-0331 of ICSD files) and non-transformed WC reinforcement (reference pattern number 00-004-0787 of ICDD and 01-072-0097 of ICSD, respectively). The formation of any other phases, such as $\mathrm{Al}_{4} \mathrm{C}_{3}$ or $\mathrm{Al}_{4} \mathrm{~W}$, was not detected. A similar study revealed that the products resulting from the transformation during sintering depend on the particle size of the powder [15].

EBSD analysis performed on the non-reinforced and reinforced specimens reveal that the strengthening of this composite can also be attributed to the grain refinement mechanism. This effect is clearly seen comparing Figure $6 a, b$. The densified pure Al has an average grain size of $3.4 \mu \mathrm{m}$, smaller than the $\mathrm{D}_{50}$ of the Al powder, which is more than double that of the Al-1 vol.\% WC composite (average grain size of $1.5 \mu \mathrm{m}$, excluding the second phase particles). The grain distribution charts (Figure 6c,d) show that grains larger than $10 \mu \mathrm{m}$ are almost absent in the composite microstructure. This refinement has been caused by the presence of ultrafine WC particles and/or by the formation of $\mathrm{Al}_{12} \mathrm{~W}$ that hindered the grain boundary movement process during sintering. Making the grain boundary movement difficult can also have negative aspects because it delays the elimination of pores during sintering. However, this effect can be overcome by increasing the sintering time (see Figure 3). 


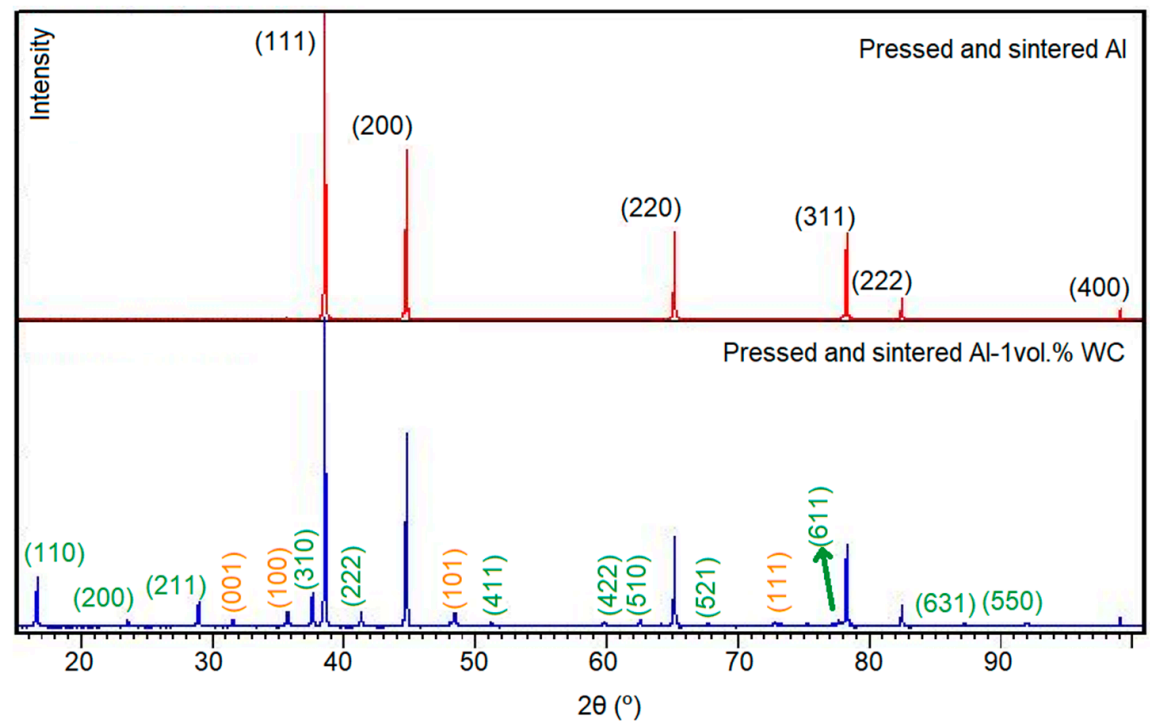

Figure 5. Diffractograms of sintered $\mathrm{Al}$ and $\mathrm{Al}-1$ vol.\% WC. The composite shows $\mathrm{Al}, \mathrm{Al}_{12} \mathrm{~W}$ and WC peaks. The Miller indices (hkl) of the diffraction peaks of $\mathrm{Al}, \mathrm{Al}_{12} \mathrm{~W}$ and $\mathrm{WC}$ are shown in black, green and brown, respectively.

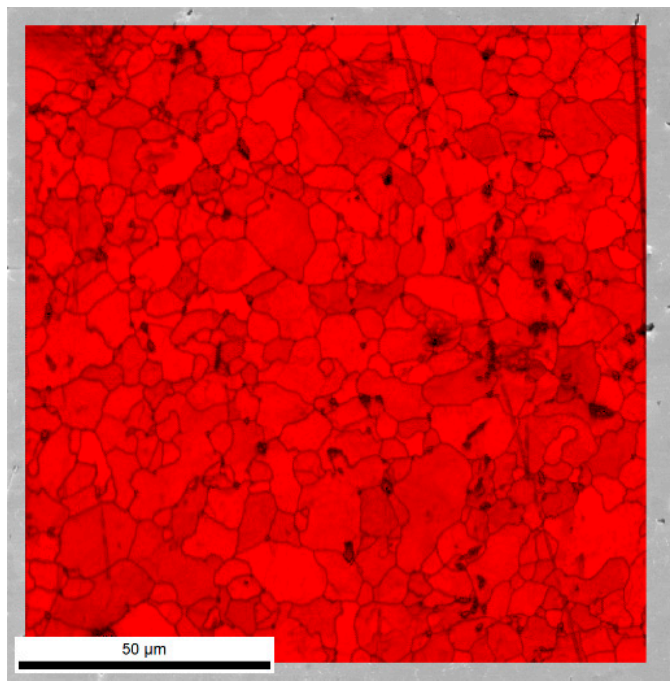

(a)

Grain Size (diameter)

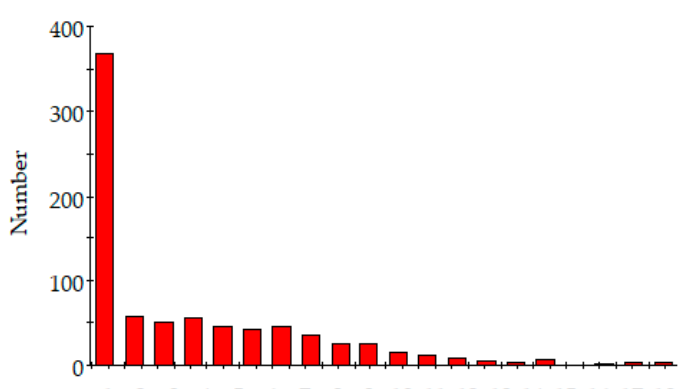

Grain Size (Diameter) [microns]

(c)

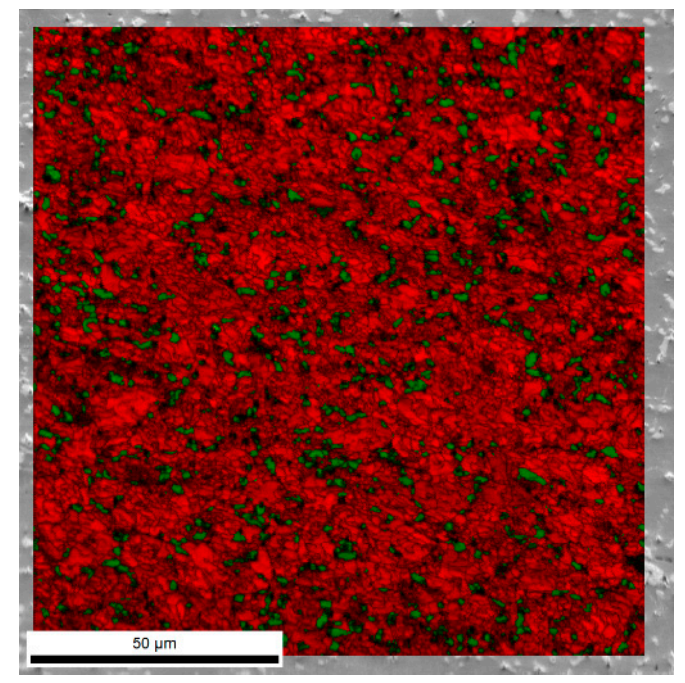

(b)

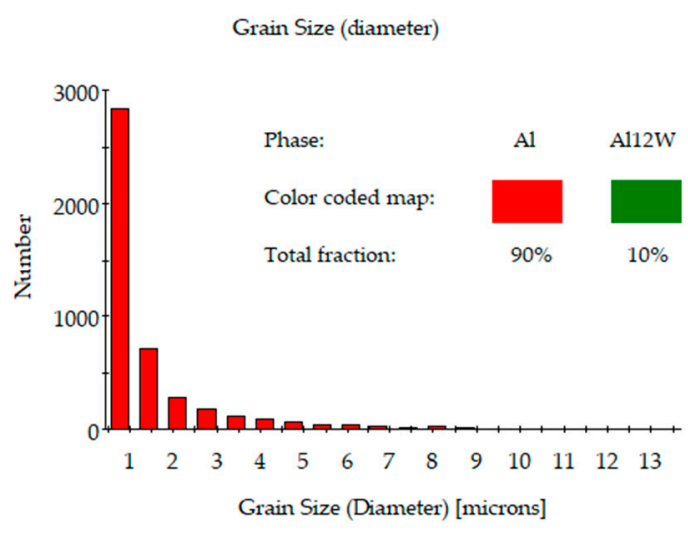

(d)

Figure 6. Phase map (EBSD/SEM) of (a) non-reinforced Al and (b) Al-WC composite; grain size distribution of (c) non-reinforced $\mathrm{Al}$ and (d) Al-WC composite. 
This EBSD analysis also confirmed the formation of the $\mathrm{Al}_{12} \mathrm{~W}$ phase (green zones in Figure $6 \mathrm{~b}$ ) in the microstructure, for almost $10 \%$.

This microstructural characterization demonstrated that several factors must be considered when analyzing the mechanical response of aluminum reinforced with $W C$, some of them with the opposite effect. For example, the formation of $\mathrm{Al}_{12} \mathrm{~W}$ is achieved by the partial or total reaction of the WC particles with the $\mathrm{Al}$ matrix.

\subsection{Mechanical Behaviour of the Al-1 vol.\% WC}

The strengthening behavior of the Al-1 vol.\% WC produced in this study was evaluated by micro hardness measurements. The graph illustrated in Figure 7 shows the hardness evolution as a function of the processing conditions (sintering temperature, holding time and compaction pressure). The increase in sintering temperature by $10^{\circ} \mathrm{C}$ (from 630 to $640{ }^{\circ} \mathrm{C}$ ) promotes an increase in hardness from 23 to $35 \mathrm{HV}$, i.e., an increase of $52 \%$; however, quadrupling the holding time (from 0.5 to $2 \mathrm{~h}$ ) caused only a $25 \%$ increase in hardness (from 28 to $35 \mathrm{HV}$ ). Moreover, doubling the compaction pressure (from 76 to $152 \mathrm{MPa}$ ) resulted in an increase in hardness of only $11 \%$ (from 35 to $39 \mathrm{HV}$ ).

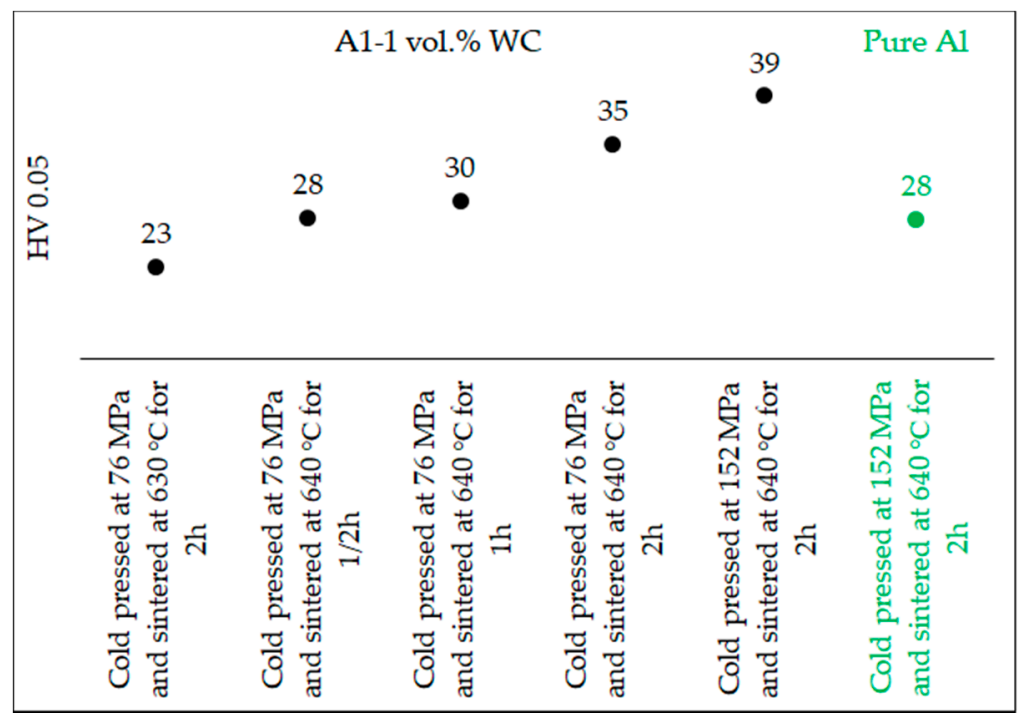

Figure 7. Microhardness values as a function of processing conditions for the Al-WC composite and the non-reinforced Al.

These results highlight the effectiveness of temperature in increasing hardness. This effect cannot be dissociated from the increase in density with processing conditions, as previously reported. Some authors have presented similar results, the growth of hardness with densification being highly affected by the sintering temperature [16].

The mechanical response of the hardest composite was also analyzed using tensile and three-point bending tests. For comparison, non-reinforced $\mathrm{Al}$ sintered under the same conditions was also tested. Table 2 shows the mechanical properties of non-reinforced $\mathrm{Al}$ and $\mathrm{Al}-1$ vol.\% WC composite produced at $152 \mathrm{MPa} / 640^{\circ} \mathrm{C} / 2 \mathrm{~h}$ in high vacuum $\left(5 \times 10^{-4} \mathrm{~Pa}\right)$. From the analysis of the table, the strengthening effect of the addition of WC is evident, promoting an increase in yield strength for $75 \%$ and in the ultimate strength for 35\%, associated with the increase in hardness by $39 \%$ mentioned above. This mechanical tensile behavior of the composite occurs with a comparative reduction in ductility for $3 \%$. The strengthening effect was also detected in bending tests; the flexural strength of the composite is $58 \%$ greater than that of unreinforced aluminum. The maximum bend angle has been achieved without fracturing in both specimens; no cracks were visible on the most deformed surfaces. 
Table 2. Mechanical properties of non-reinforced $\mathrm{Al}$ and of $\mathrm{Al}-1$ vol.\% WC composite.

\begin{tabular}{ccccc}
\hline Composition & Ys ${ }^{*}(\mathbf{M P a})$ & UTS $\mathbf{( M P a )}$ & Elongation $\mathbf{( \% )}$ & Flexural Strength (MPa) \\
\hline Pure Al & $\sim 63$ & 110 & 19 & 336 \\
Al-WC & $\sim 110$ & 148 & 16 & 532 \\
\hline \multicolumn{5}{r}{ *-determined through the $0.2 \%$ offset line on the graph by regression method. }
\end{tabular}

A failure analysis was performed on the fracture surfaces of the tensile specimens (Figure 8); SEM observations revealed the presence of dimples in samples of non-reinforced $\mathrm{Al}$ and $\mathrm{Al}-1 \mathrm{vol} . \%$ WC. These dimples are associated with a ductile fracture with the crack formed from microcavities. In the composite, the formation of those microcavities is facilitated, reducing the ductility, by the decohesion in the particle/matrix interface. As can be seen in Figure $8 \mathrm{~d}$, there are areas with particles embedded in the bottom of the dimples of the composite specimen.

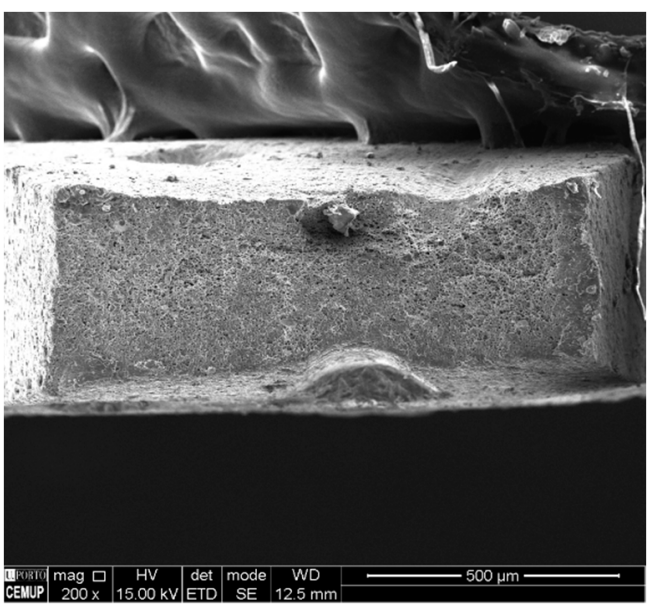

(a)

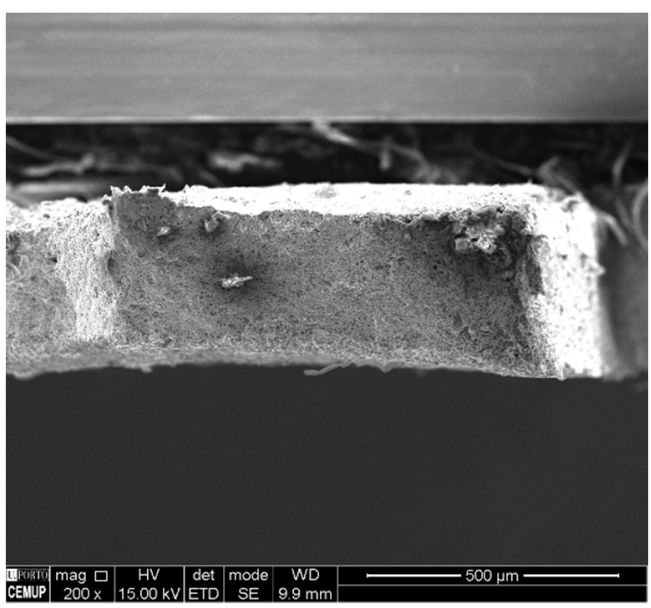

(c)

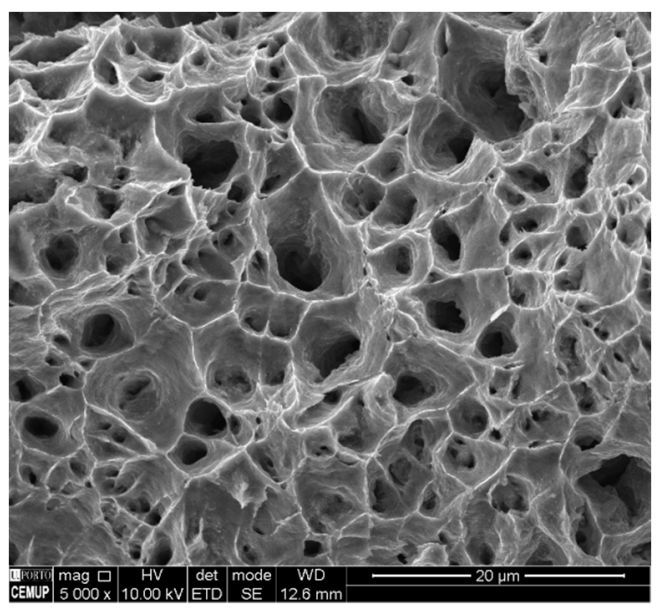

(b)

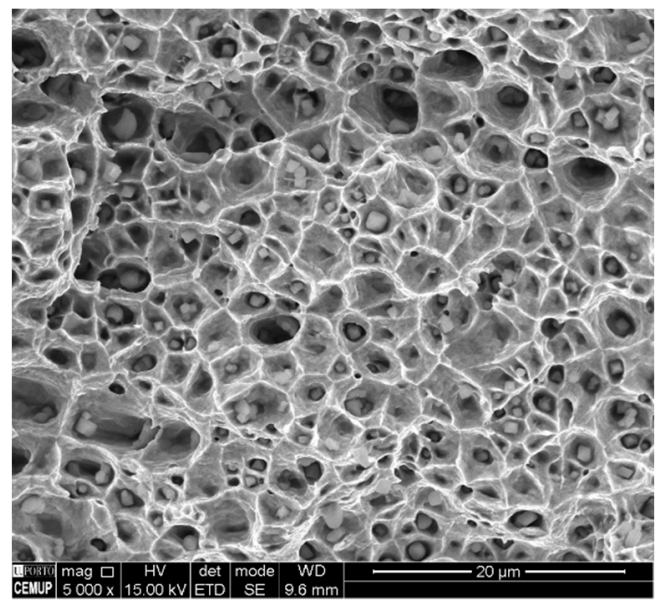

(d)

Figure 8. SEM/SE images of fracture surfaces at two magnifications of: $(\mathbf{a}, \mathbf{b})$ Non-reinforced $\mathrm{Al}$ specimen; (c,d) Al-WC composite.

The decohesion at the particle/matrix interface (seen in Figure 8d) indicates that the load transfer mechanism becomes less effective with the increase of plastic deformation.

WC particles were expected to increase the wear resistance of the Al-WC composite compared to non-reinforced Al. However, the results of abrasive wear resistance during ball cratering test showed the opposite, as displayed in Figure 9. In this figure, the increase in wear can be observed with the 
increase in the applied load (Figure 9a) and with the increase in the sliding distance (Figure 9b), always maintaining the non-reinforced $\mathrm{Al}$ with a better performance.

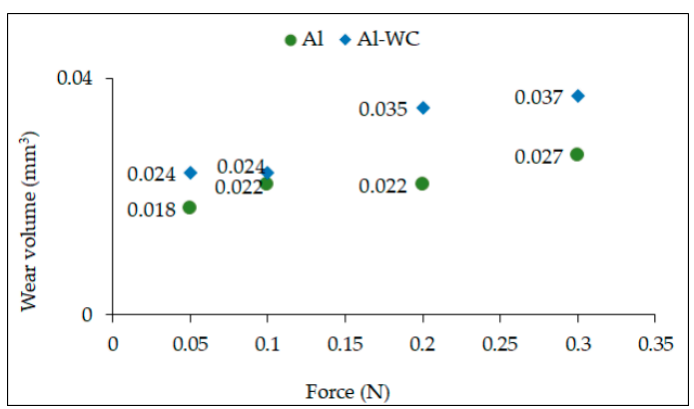

(a)

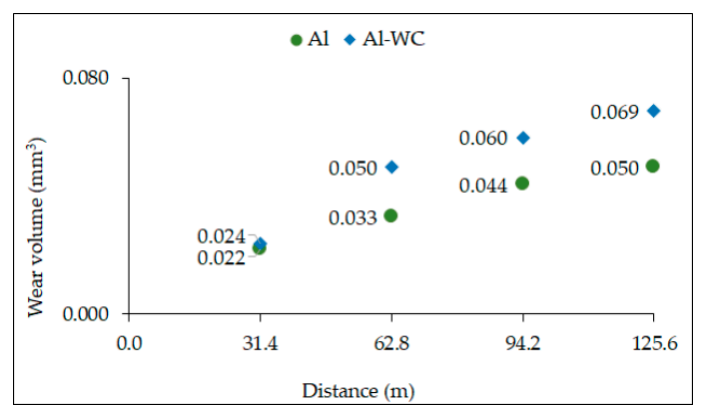

(b)

Figure 9. Wear abrasive resistance results, performed on specimens produced with $152 \mathrm{MPa} / 640{ }^{\circ} \mathrm{C} / 2$ $\mathrm{h} /$ high vacuum $\left(5 \times 10^{-4} \mathrm{~Pa}\right)$, (a) for different loads with a distance of $31.4 \mathrm{~m}$ and (b) for different distances with $0.1 \mathrm{~N}$ load.

Microscopic observations (Figure 10) indicate that the wear mechanism was grooving for both the non-reinforced $\mathrm{Al}$ and the $\mathrm{Al}-\mathrm{WC}$ composite; however, the groove morphology does not look the same. These observations seem to indicate that the particles of the hard phases, $\mathrm{WC}$ and $\mathrm{Al}_{12} \mathrm{~W}$, did not maintain the bond to the aluminum matrix and acted as extra abrasives, contributing to more significant abrasion. Other authors mentioned similar behavior, observing the influence of the insufficient bonding between the matrix and the reinforcements [17].

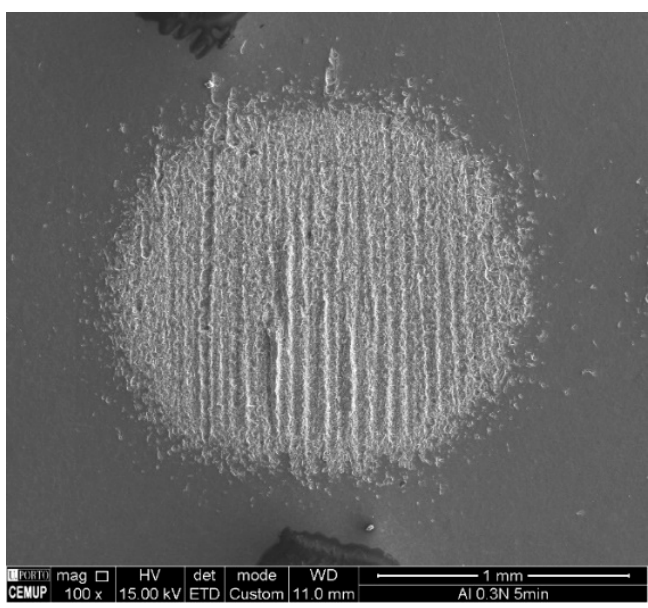

(a)

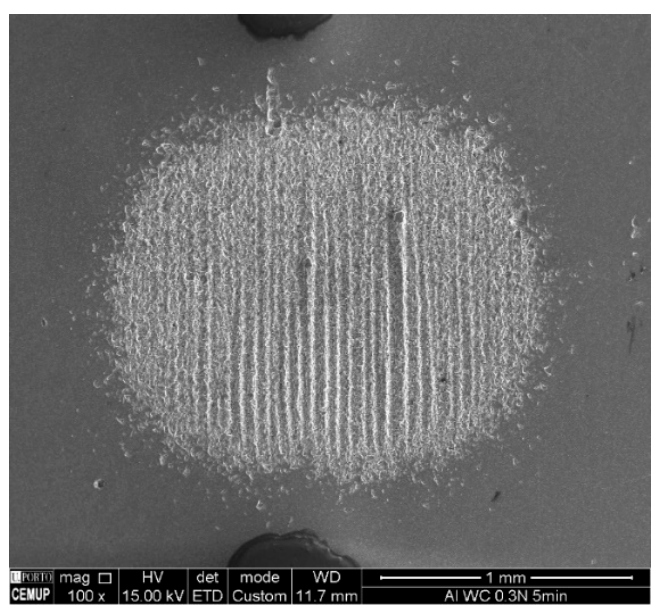

(b)

Figure 10. SEM/SE images showing craters and morphology of the grooves on: (a) Non-reinforced Al and (b) Al-WC composite.

In summary, the mechanical properties (except abrasive wear resistance) of a pure $\mathrm{Al}$ increased with the addition of $1 \mathrm{vol} . \%$ of ultra-fine WC powder that was dispersed with the Al powder by the assisted sonication technique. The powders mixture was cold compacted with $152 \mathrm{MPa}$ and densified at $640{ }^{\circ} \mathrm{C}$ for $2 \mathrm{~h}$ in high vacuum. The comparison of the $\mathrm{Al}-1$ vol.\% WC with the non-reinforced $\mathrm{Al}$, both produced under the mentioned processing conditions, shows that the composite is $39 \%$ harder and exhibits an increase of $75 \%, 35 \%$ and $58 \%$ in yield strength, ultimate strength and flexural strength, respectively. Microstructural characterizations were performed to identify the strengthening mechanism(s) activated in this system. The primary mechanism must be associated with the presence of $\mathrm{WC}$ and $\mathrm{Al}_{12} \mathrm{~W}$ particles. The latter particles are coarser, more abundant and result from the 
reaction of the $\mathrm{WC}$ with $\mathrm{Al}$ during sintering. The $\mathrm{WC}$ and $\mathrm{Al}_{12} \mathrm{~W}$ particles are effective obstacles to the movement of dislocations, explaining the increase in mechanical resistance. Another mechanism associated with this strengthening is the grain refinement resulting from restrictions on the movement of grain boundaries (and powder particles surfaces) caused by these particles. This mechanism has the advantage of not adversely affecting the ductility of the composite. The load transfer mechanism is also important in strengthening the composite, being more effective at the beginning of the plastic deformation where there are still no discontinuities between the particles and the interface.

\section{Conclusions}

An assisted sonication technique dispersed aluminum powder particles with $\mathrm{D}_{50}$ of $10 \mu \mathrm{m}$ with $1 \%$ by vol. of tungsten carbide powder particles with a $\mathrm{D}_{50}$ of $0.33 \mu \mathrm{m}$. This powder mixture was cold compacted and vacuum sintered. The densification of the Al-1 WC composite was obtained by increasing the sintering temperature and the holding time; processing conditions also contributing to the increase in hardness. The hardness of this composite, produced after compacting at $152 \mathrm{MPa}$ and sintering at $640{ }^{\circ} \mathrm{C}$ for $2 \mathrm{~h}$ in vacuum, increased by $39 \%$ compared to non-reinforced Al. The yield strength and ultimate tensile strength of the composite increased by $75 \%$ and $35 \%$, respectively, with a reduction in elongation for only $3 \%$. The ductile aspect of the fracture surface, with small dimples, is consistent with this maintenance of elongation. However, this composite did not show resistance to abrasive wear, as assessed by the ball crater test. This mechanical behavior is associated with the WC particles and the $\mathrm{Al}_{12} \mathrm{~W}$ phase formed during sintering. In addition to the presence of these particles, the grain refinement also contributed to the strengthening and ductility of this Al- 1 vol.\% WC composite.

Author Contributions: Conceptualization, O.E.; formal analysis, O.E.; funding acquisition, M.F.V.; investigation, O.E.; methodology, O.E.; resources, M.F.V.; supervision, M.T.V. and M.F.V.; validation, M.T.V. and M.F.V.; visualization, O.E.; writing-original draft, O.E.; writing—review and editing, M.T.V. and M.F.V. All authors have read and agreed to the published version of the manuscript.

Funding: This work was supported by Portuguese funds through UIDB/00285/2020, UIDB/50022/2020 and UIDP/50022/2020 projects funded by FCT (Fundação para a Ciência e a Tecnologia), Portuguese public agency.

Acknowledgments: The authors would like to express thanks from CEMUP (Centro de Materiais da Universidade do Porto) for assistance with SEM, the department of Mechanical Engineering at the Faculty of Engineering-University of Porto for providing the Ball cratering test equipment, and also CINFU (Centro de Formação Profissional da Indústria de Fundição) for cutting aluminium specimens.

Conflicts of Interest: The authors declare no conflict of interest.

\section{References}

1. Williams, J.C.; Starke, E.A. Progress in structural materials for aerospace systems ${ }^{1}$. Acta Mater. 2003, 51, 5775-5799. [CrossRef]

2. Koli, D.K.; Agnihotri, G.; Purohit, R. Advanced Aluminium Matrix Composites: The Critical Need of Automotive and Aerospace Engineering Fields. Mater. Today Proc. 2015, 2, 3032-3041. [CrossRef]

3. Baron, C.; Springer, H. Properties of particle phases for metal-matrix-composite design. Data Brief 2017, 12, 692-708. [CrossRef] [PubMed]

4. WC Properties. Available online: http://matweb.com/search/datasheet.aspx?MatGUID= e68b647b86104478a32012cbbd5ad3ea (accessed on 21 August 2020).

5. Evirgen, A.; Öveçoğlu, M.L. Characterization investigations of a mechanically alloyed and sintered Al-2wt\%Cu alloy reinforced with WC particles. J. Alloys Compd. 2010, 496, 212-217. [CrossRef]

6. Liu, C.; Wang, Q.; Jia, Y.; Zhang, B.; Jing, R.; Ma, M.; Jing, Q.; Liu, R. Evaluation of mechanical properties of 1060-Al reinforced with WC particles via warm accumulative roll bonding process. Mater. Des. 2013, 43, 367-372. [CrossRef]

7. Ravikumar, K.; Kiran, K.; Sreebalaji, V. Characterization of mechanical properties of aluminium/tungsten carbide composites. Measurement 2017, 102, 142-149. [CrossRef] 
8. Huang, G.; Hou, W.; Shen, Y. Evaluation of the microstructure and mechanical properties of WC particle reinforced aluminum matrix composites fabricated by friction stir processing. Mater. Charact. 2018, 138, $26-37$. [CrossRef]

9. Borodianskiy, K.; Zinigrad, M. Modification Performance of WC Nanoparticles in Aluminum and an Al-Si Casting Alloy. Met. Mater. Trans. A 2016, 47, 1302-1308. [CrossRef]

10. Casati, R.; Vedani, M. Metal Matrix Composites Reinforced by Nano-Particles-A Review. Metals 2014, 4, 65-83. [CrossRef]

11. Samal, C.; Parihar, J.; Chaira, D. The effect of milling and sintering techniques on mechanical properties of $\mathrm{Cu}$-graphite metal matrix composite prepared by powder metallurgy route. J. Alloys Compd. 2013, 569, 95-101. [CrossRef]

12. Razavi, M.; Mobasherpour, I. Production of aluminum nano-composite reinforced by tungsten carbide particles via mechanical milling and subsequent hot pressing. Int. J. Mater. Res. 2014, 105, 1103-1110. [CrossRef]

13. Simon, A.; Lipusz, D.; Baumli, P.; Balint, P.; Kaptay, G.; Gergely, G.; Sfikas, A.; Lekatou, A.; Karantzalis, A.; Gácsi, Z. Microstructure And Mechanical Properties Of Al-WC Composites. Arch. Met. Mater. 2015, 60, 1517-1521. [CrossRef]

14. German, R. Thermodynamics of sintering. In Sintering of Advanced Materials; Elsevier BV: Amsterdam, The Netherlands, 2010; pp. 3-32.

15. Zhang, H.; Feng, P.; Akhtar, F. Aluminium matrix tungsten aluminide and tungsten reinforced composites by solid-state diffusion mechanism. Sci. Rep. 2017, 7, 12391. [CrossRef]

16. Li, B.; Liu, Y.; Li, J.; Cao, H.; He, L. Effect of sintering process on the microstructures and properties of in situ TiB2-TiC reinforced steel matrix composites produced by spark plasma sintering. J. Mater. Process. Technol. 2010, 210, 91-95. [CrossRef]

17. Doni, Z.; Alves, A.C.; Toptan, F.; Pinto, A.M.P.; Rocha, L.A.; Buciumeanu, M.; Palaghian, L.; Silva, F.S. Tribocorrosion behaviour of hot pressed $\mathrm{CoCrMo}-\mathrm{Al}_{2} \mathrm{O}_{3}$ composites for biomedical applications. Tribol. Mater. Surf. Interfaces 2014, 8, 201-208. [CrossRef]

Publisher's Note: MDPI stays neutral with regard to jurisdictional claims in published maps and institutional affiliations.

(C) 2020 by the authors. Licensee MDPI, Basel, Switzerland. This article is an open access article distributed under the terms and conditions of the Creative Commons Attribution (CC BY) license (http://creativecommons.org/licenses/by/4.0/). 